\title{
LA PROBLEMÁTICA ACTUALIDAD DEL COSMOPOLITISMO
}

\author{
The Problematic Actuality of Cosmopolitanism
}

\author{
Albert Muñoz Miralles \\ DOI: 10.26754/ojs_arif/a.rif.202013485
}

\begin{abstract}
RESUMEN
El cosmopolitismo es una antigua aspiración filosófica, reivindicando aquello que compartimos como seres humanos más allá de las pertenencias particulares. Se expresó como un proyecto político, como una forma cultural y como una demanda moral. La ciudad ofrece los ingredientes para la formación de una sociabilidad cosmopolita y una forma de vida democrática, aunque siempre amenazada por el retraimiento particularista. La comprensión del cosmopolitismo de Richard Sennett engarza agudamente en esta problemática, que cobra mayor actualidad en relación a la expansión de los procesos globalizadores. Sin embargo, la multiplicación de resistencias observable hoy en día representa un nuevo desafío para el proyecto cosmopolita.
\end{abstract}

PALABRAS CLAVE: cosmopolitismo, democracia, ciudadanía, globalización, nueva economía.

\begin{abstract}
Cosmopolitanism is an old philosophical aspiration, claiming what we share as human beings beyond private belongings. It was expressed as a political project, as a cultural form and as a moral demand. The city offers the elements to make up a cosmopolitan sociability and a democratic way of life, although always threatened by particularist withdrawal. The understanding of cosmopolitanism by Richard Sennett engages sharply in this problematic, which becomes more present in relation to the expansion of the globalizing processes. However, the noticeable multiplication of resistances represents a new challenge for the cosmopolitan project.
\end{abstract}

KEYWORDS: cosmopolitanism, democracy, citizenship, globalization, new economy. 


\section{Planteamiento}

El tema del cosmopolitismo adquirió una renovada actualidad con el nuevo siglo, debido en buena medida al influjo de la globalización, que lleva aparejado un incremento de los movimientos migratorios, una creciente urbanización, la elevación de problemas y retos que presentan una dimensión mundial — reclamando la acción de instituciones y organismos supranacionales-, o una ampliación exponencial de los canales de información, facilitando la actividad de movimientos sociales globales ${ }^{1}$. Como consecuencia, se produce un cuestionamiento de los límites del poder y la influencia de los estados, al mismo tiempo que se revela la pertinencia de repensar el sentido de la identidad, lo que a su vez reclama una renovada reflexión sobre la ciudadanía y los derechos.

Pero más recientemente, estamos asistiendo al florecimiento de movimientos que recelan de la globalización, propugnando por diferentes sendas un retorno a una comprensión más limitada del mundo, apegada de nuevo a lo territorial. La intensificación del fundamentalismo religioso - y su expresión más feroz en forma de terrorismo- , el auge de movimientos nacionalistas o de extrema derecha en occidente reclamando políticas anti-migratorias y proteccionistas, en buena medida derivadas de la reciente crisis financiera, patentizan las contradicciones de la globalización - los triunfos del brexit o de Trump serían sintomáticos de este movimiento reactivo $-^{2}$. Inevitablemente provocan también una crisis del espíritu que animó la formación de la comprensión cosmopolita de la realidad humana.

Por ello, se trata de reivindicar la vigencia del proyecto cosmopolita ante la reiteración particularista, expandiendo el horizonte de interés y reflexión más allá de los límites de la comunidad o la nación, incidiendo en el valor del ser humano para hacer frente a unos retos, oportunidades y problemas que presentan hoy una dimensión ineludiblemente global.

Para ello, es preciso aclarar qué pueda entenderse por cosmopolitismo hoy en día, ya que se trata de una idea de gran calado en el pensamiento occidental, sobre todo a partir de la Ilustración. Se forjó como un horizonte moral y político que pretendía superar las divisiones y disputas nacionales y alentar una comprensión del ser humano que trascendiera las contingencias propias de la pertenencia grupal y la identidad particular, resaltando la igualdad fundamental. Si bien en los

1 No obstante, habría que evitar identificar cosmopolitismo con globalización (Delanty 2006: 31-32).

2 En general, se observa una retracción de las políticas pluralistas y cosmopolitas (Raco, 2018). 
últimos años se ha empezado a considerar más como un fenómeno empírico que como un ideal normativo, analizando cómo se incorpora la orientación de apertura hacia los otros en las diversas prácticas e instituciones en un mundo global (Iragashi y Saito 2014: 223-224).

Las diferentes discusiones y propuestas acerca del cosmopolitismo se articulan en torno a tres vertientes reconocibles de esta idea: política, cultural y moral. La primera giraría en torno a la necesidad de establecer instituciones efectivas de alcance global; la segunda apuntaría a la idea de una cultura global común y a la habilidad personal para manejarse en contextos culturales variados; $y$ finalmente se enfatizaría que todos los seres humanos comparten una valor moral fundamental ante el que el lugar de nacimiento se muestra irrelevante (Kymilcka y Walker 2012: 2). Sería en la vertiente política donde se promovería el regreso del tema del cosmopolitismo, atendiendo a las cuestiones de democracia y ciudadanía problematizados con la globalización (Delanty 2006: 29).

La noción de cosmopolitismo abarca, así pues, tanto una dimensión política como socio-cultural, o filosófica, por lo que es posible abordarla desde distintos enfoques y prioridades teóricas, pero reclamando en cualquier caso la participación de una reflexión de tipo moral, reclamando que se reconozca a los seres humanos en cuanto tales ${ }^{3}$.

Desde una vertiente política o jurídica se atiende al problema de las relaciones internacionales, o se debate sobre la viabilidad de construir instituciones transnacionales que dispongan de un poder efectivo, aunque también aflora la cuestión del respeto de los derechos humanos más allá de los márgenes de la protección que pueda aportar la pertenencia a un estado en forma de ciudadanía — entendida aquí estrictamente, por tanto, como la condición de reconocimiento a un individuo como miembro de pleno derecho de una determinada comunidad política ordenada como un estado de derecho- (García Pascual 2003: 1). En ese sentido, más allá de esa dimensión institucionalizada, puede enfatizarse la emergencia de una nueva sociedad civil de carácter global, o la posibilidad de participar de diferentes afiliaciones o intereses (Vertovec y Cohen 2012: 1-22). La consideración de una posible ciudadanía cosmopolita se revela ya de entrada, por tanto, como un proyecto intrínsecamente problemático. Más si cabe cuando la constitución de la identidad se efectúa en un escenario incierto, cambiante y heterogéneo.

3 Delanty denuncia que la escisión entre lo político y lo social en el pensamiento moderno supuso la restricción del ideal cosmopolita al ámbito político, relegando lo social al terreno de lo particular (Delanty 2006: 26). 
La cuestión del cosmopolitismo emerge vivamente cuando se plantea el reto de la convivencia entre grupos de variados orígenes, características e identidades cuando han de compartir un mismo espacio. La ciudad representa el espacio paradigmático donde se encuentran y cohabitan gentes diversas, hallando hoy posibilidades renovadas gracias al incremento de los flujos migratorios y comunicativos. El urbanita se enfrenta a la alteridad, toma conciencia de los límites de su propia identidad, vislumbra un horizonte humano más amplio. La aproximación a la convivencia urbana invita a orientar la reflexión sobre el cosmopolitismo hacia la dimensión cultural y formativa, aun cuando sea preciso no perder de vista la brújula moral inserta en la historia de este concepto.

Las reflexiones y propuestas que ofrece Richard Sennett en torno a la idea del cosmopolitismo enraízan en ese complejo escenario urbano, versando sobre la problemática y las oportunidades que ofrece la urbe para un desarrollo personal y de un modo de convivencia civilizado que trascienda las perspectivas grupales. Por ello, se tomará como una referencia primordial en este trabajo. Aunque se tratará de discernir hasta qué punto su comprensión del cosmopolitismo ofrece un horizonte crítico, o si bien queda restringida simplemente a perfilar un modo de vida.

Se trata de repensar su vigencia, relación y función de la idea del cosmopolitismo a la luz de los procesos globalizadores que configuran el mundo actual, tratando de ofrecer una visión integradora de la misma. Para ello seguidamente se analizará la problemática cuestión de una ciudadanía cosmopolita, para posteriormente atender a las condiciones sociales y culturales efectivas que hagan posible la formación de una conciencia y una forma de vida cosmopolitas en un escenario urbano, valorando la propuesta sennetiana.

\section{2. ¿ES POSIBLE UNA CIUDADANÍA COSMOPOLITA?}

El estatuto legal del ciudadano implica su reconocimiento oficial como pleno derecho de una comunidad política organizada desde la modernidad en forma de estado de derecho (Cortina 2005: 39). La noción de ciudadanía parece así de entrada sugerir una dialéctica de inclusión y exclusión, de identidad y diferencia, que desafía las aspiraciones morales universalistas restringiendo su ámbito de aplicación a la comunidad política concreta ${ }^{4}$. La elaboración de una "teoría de la ciudadanía" se hace eco inevitablemente de las controversias entre las exigencias

\footnotetext{
4 Por ello Habermas entendería que la noción de ciudadanía, como categoría política, halla su principio de legitimación al margen del ámbito de lo moral (Cortina 2000: 776-777).
} 
de justicia - representadas por las tradiciones liberales y universalistas - y las necesidades de pertenencia e identidad — reclamadas por planteamientos comunitarios-, reflejando dos caras que presenta la integración de los individuos en comunidades políticas (Id. 21-35).

La idea de una ciudadanía cosmopolita enraíza directamente en esta problemática, emergiendo como un proyecto universalista que reclama la necesidad de trascender los marcos jurídico-políticos existentes que son, paradójicamente, los que otorgan la condición de ciudadanos a sus miembros (Id. 37). Por ello, la noción de "ciudadano del mundo", en tanto no sea análoga con la ciudadanía estatal, manifiesta una inquietante ambigüedad, apuntando en último término a la situación de los desposeídos o desprotegidos (Calhoun 2008: 109-111). En consecuencia, un reconocimiento de la condición cosmopolita sigue planteando un problema fundamental, la vigencia de los derechos humanos a lo ancho del planeta (Muguerza 2004: 18). Pues es común que de hecho se produzca un reconocimiento desigual de los derechos, en virtud precisamente de la posesión o no de la ciudadanía.

Emerge así, en primer lugar, un problema de índole jurídico-político, puesto que si la condición de ciudadanía requiere de la inserción en un estado que la reconozca y garantice, hablar de una ciudadanía cosmopolita parecería reclamar la necesidad de algún tipo de comunidad política de alcance mundial. Si desde un punto de visto jurídico la ciudadanía supone el reconocimiento de derechos, una "ciudadanía cosmopolita" puede interpretarse como una categoría vacía si no conlleva una atribución efectiva de derechos. Por ello, el debate en torno al cosmopolitismo ha versado históricamente sobre la posibilidad y la necesidad de construir un estado mundial, o bien alguna forma de comunidad jurídica internacionalmente reconocida, que propiciara la pacificación de las relaciones internacionales y la salvaguarda de los derechos individuales a lo largo del planeta (García Pascual 2003). En ese sentido, ya Kant apuntaba el horizonte de un nuevo orden global, que permitiera superar el estado de naturaleza que define las relaciones interestatales, para constituir unas estructuras e instituciones que consagraran la realización universal de los principios morales garantizando el sostenimiento de la paz (Granja 2010: 168-179 y 234-247).

Aunque no parece ya muy realista el proyecto de constituir una verdadera comunidad política mundial, y ni tan siquiera se deja entrever una aproximación a un orden internacional pacificado — la ONU hace patente sus limitaciones a este respecto-, lo cierto que es que la pujanza de la globalización conlleva necesariamente un cuestionamiento de los límites tradicionales de la soberanía y, consecuentemente, de la ciudadanía, en la medida en que nos sumergimos en un 
mundo en que sus diversas partes son cada vez más interdependientes, en que los flujos migratorios se intensifican y en el que los problemas y desafíos que afrontan las sociedades superan habitualmente una dimensión meramente local o regional - ecológicos, financieros, laborales, tecnológicos- Por ello, adquiere una vigencia renovada en nuestro tiempo la idea de una ciudadanía cosmopolita (García Pascual 2003: 2-3; Mesa 2006: 12; Kymilcka y Walker 2012: 2).

Se trata de hacer frente a la dimensión global de los retos actuales, para lo cual una concepción tradicional de la ciudadanía y la acción política o social se revela limitada e impotente. De manera destacada, es preciso conferir mayor confianza y estabilidad a una economía globalizada entregada a los excesos especulativos, urgiendo establecer nuevas reglas de alcance mundial (Lipovetsky 2011: 27-28). Sin embargo, las instituciones transnacionales existentes presentan importantes déficits democráticos que merman su autoridad y legitimidad, concediendo a los estados una nueva oportunidad en el fomento de los objetivos cosmopolitas (Kymilcka y Walker 2012: 6-7). Aunque la globalización impulsa el protagonismo de otros actores institucionales, al margen de los gobiernos, con capacidad de influir en las decisiones que afectan al espacio público (García Marzá 2013: 31).

La responsabilidad se distribuye, consecuentemente, entre múltiples instancias. Por ello, se apela hoy a una noción de gobernanza entendida como un conjunto de procesos de toma compartida de decisiones en que participan actores diversos - ya no sólo políticos, también procedentes del mercado o la sociedad civilsituados en diferentes niveles, implicando una descentralización del poder, una forma de organización en red, y una difuminación de los límites entre el estado y la sociedad civil (González Esteban 2013: 4-9). La multiplicación de los centros decisorios y de poder reclama, por tanto, una redefinición actual del proyecto de una ciudadanía cosmopolita en el marco de una comunidad política cosmopolita cuyas múltiples interconexiones le confieren un aspecto en red (Mesa 2006: 14)5. Pero, puesto que la legitimidad democrática de los diversos actores así como la transparencia e inclusión de los procesos decisorios no está garantizada, la cuestión de una gobernanza cosmopolita se plantea no sólo como un problema político, sino también ético.

Tras las cuestiones jurídico-políticas que genera la idea de la ciudadanía cosmopolita, vinculadas al problema de la gobernanza, asoma una cuestión más

5 En ese sentido, cabría destacar la propuesta de Held de una soberanía cosmopolita entendida como "conjunto de entornos interconectados de autoridad pública formados y delimitados por un marco jurídico cosmopolita global”. Citado por González Esteban 2013: 24. 
profunda de índole moral, que incidiendo en la dialéctica entre pertenencia y universalidad, atañe a la definición del ser humano. Pero a su vez, en cuanto compromete la identidad que adquieren y manifiestan las personas y los grupos, implica también una vertiente socio-cultural, que tiene que ver con las formas de vida y los valores que comporta un horizonte cosmopolita de la convivencia global.

La emergencia de la globalización, la expansión capitalista y las facilidades en la comunicación propiciadas por los avances tecnológicos favorecen la formación de modelos culturales, formas de pensar y estilos de vida a lo largo del planeta, rebasando la dimensión local. Como resultado, se perfilan formas de identidad más flexibles o solapadas, reclamando la mencionada revisión del concepto de ciudadanía, para profundizar en la dimensión cosmopolita (Delanty 2006: 29-30). Según se expondrá en el siguiente apartado, las ciudades parecen ofrecer el marco idóneo para la formación de una identidad y un estilo de vida cosmopolitas.

El cosmopolitismo indica la apertura al mundo, el encuentro con formas de vida diferentes que invita a repensar o reconfigurar la identidad previamente adquirida. Por ello, diversos autores lo identifican con una condición socio-cultural, la propia de un mundo altamente interconectado. Puede reconocerse, consecuentemente, como una capacidad para incorporar influencias variadas o para moverse cómodamente entre las diferencias (Calhoun 2008: 107) ${ }^{6}$. Delanty, de manera más crítica, lo concibe como un principio de apertura al mundo que se manifiesta cuando tiene lugar un encuentro de lo local con lo global, impulsando la transformación social.

Lipovestsky, por su parte, propone la noción de cultura-mundo para designar la experiencia de un mundo interconectado e interdependiente en que el mercado se revela como la principal fuerza estructuradora de las actividades, organizaciones y formas de pensamiento, dispuesta a satisfacer las demandas hedonistas de las masas, superando los particularismos, e impulsando una conciencia del mundo como fenómeno verdaderamente planetario. Por ello, se instala una nueva forma de cosmopolitismo, que deja de ser un ideal humanista abstracto, para revelar un rostro

\footnotetext{
${ }^{6}$ El cosmopolitismo puede identificarse así con una postura intelectual y estética de apertura hacia el otro - Hannerz-, o con una práctica o habilidad para visitar distintos sistemas de significado sin llegar a ser parte de ellos —el yo cosmopolita de Waldon—, etc. (Vertovec y Cohen 2002: 7-14). Aunque habría que evitar adherirse a una comprensión individualista del proceso de formación de la identidad cosmopolita — en tanto abre la posibilidad de liberarse de las ataduras a la cultura nativa—, que subestime la influencia decisiva de la dimensión socio-cultural (Skovgaard-Smith y Poulfelt 2017).
} 
multidimensional, acorde con el ritmo de cambio de permanente y la hipertrofia cultural y creativa que genera la era global (Lipovetsky 2011: 11-27).

Así, hay que advertir que aun cuando el marco existente puede parecer favorable para la formación una cultura global de índole cosmopolita, lo que esté sucediendo puede representar más bien un mero predominio del consumismo en detrimento de una gama más variada de experiencias con la diversidad, que puede llegar a percibirse como un proceso de homogeneización occidentalizadora (Ibid.; Verovec y Cohen 2002: 7). Ciertamente, el acceso a las oportunidades que ofrece la globalización se está distribuyendo asimétricamente entre las distintos rincones del planeta así como entre los grupos sociales, y como consecuencia sólo una minoría sigue disfrutando realmente de una experiencia cosmopolita de la diversidad (Sassen 2003: 15-33; Calhoun 2008; Kymlicka y Walker 2012: 3). La posibilidad de conformar una cultura y un modo de vida cosmopolitas se revela hoy en día, así pues, como un proyecto no exento de ambigüedad.

La cuestión de la identidad se vuelve más enrevesada, ciertamente, cuando los marcos referenciales, previamente acotados de manera más definida a un territorio o una tradición histórica determinada, se ven desbordados por los procesos económicos, tecnológicos y sociales que caracterizan a nuestro siglo. La existencia de sociedades plurales y multiculturales en el complejo escenario que dibuja la globalización incita a revisar la dimensión de pertenencia ligada a la noción tradicional de ciudadanía, puesto que la existencia social cotidiana se abre inevitablemente al encuentro con realidades diferentes que cuestiona la fijeza de los valores y costumbres arraigados, reclamando la toma en consideración, cuanto menos, de una perspectiva que incorpore un horizonte cosmopolita. Más aún teniendo en cuenta la dimensión global que adquieren los problemas más acuciantes en nuestro tiempo. Por ello el empeño en aferrarse a una inserción emocional, vital e identitaria limitada a la comunidad específica se revela como una postura miope e incompleta.

Las realidades sociales, económicas, políticas y éticas actuales transforman la propia noción de ciudadanía, que ya no puede restringirse a la participación de una comunidad política concreta, revelando una aspiración cosmopolita (Cortina 2005: 26-38). La ampliación del concepto de ciudadanía con la inclusión de los derechos culturales supone una incorporación más clara de esa dimensión cosmopolita, particularmente visible en el afán por reconciliar la orientación universalista propia de los derechos individuales con la protección de las minorías (Delany 2007: 29). Se trata, por tanto, de dilucidar qué valores ofrece la noción de cosmopolitismo, qué puede aportar para la construcción de una teoría de la ciudadanía a la altura 
de los retos del presente. Pues la idea del cosmopolitismo sigue apuntando hoy a un problema persistente: ¿cómo se puede vivir entre las diferencias?

El cosmopolitismo implica una visión de la realidad que trasciende el horizonte de la nación, la etnicidad o la comunidad política, y ofrece consecuentemente una comprensión no-esencialista de cultura. Frente a la realidad de la diversidad y la pluralidad, pretende superar las respuestas que ofrecen los planteamientos que anteponen la pertenencia local, como las diferentes versiones del comunitarismo, sin conformarse con la solución que propone el multiculturalismo, es decir, el sostenimiento diferenciado de las distintas identidades. Los esquemas clasificatorios rígidos coartan la autonomía de unos individuos que pueden manifestar la pretensión de incluir repertorios variados de lealtades, identidades e intereses (Nava 2006: 62-63). Pero principalmente, el cosmopolitismo alude a la dimensión universal de la persona, que no queda circunscrita a las adscripciones legales e identitarias establecidas. Por ello, ha propiciado una distinción que se revela fundamental entre el "ciudadano", en tanto miembro de una determinada comunidad política, y el "hombre", como parte de la humanidad, señalando su dimensión moral fundamental (Cortina 2000: 778). En ese sentido, puede establecerse la defensa de la igualdad de derechos de todos las personas independientemente de su origen o nacionalidad (Granja 2003: 223; Sádaba 2003: 97-98; Cortina 2005: 39 ss.).

Los estoicos divisaron esa dimensión universal que nos constituye, afirmando que no sólo habitamos en la comunidad de nacimiento, pues en tanto compartimos la posesión del logos — capacidad para la razón y la palabra - formamos parte de una comunidad humana universal en la que se sitúa el horizonte moral verdadero. Pero con Kant la idea cosmopolita paso a configurar de manera destacada el pensamiento moderno, representando la existencia de una naturaleza moral común a toda la humanidad, más allá de las fronteras políticas y las identidades locales. El hecho de ser persona otorga dignidad a todos los humanos, lo que trasciende la accidentalidad de la pertenencia a una comunidad cultural o política determinada, actuando a su vez como fundamento de los derechos humanos (Cortina 2003: 6465; 2005: 252). Por ello, Kant identificaría el cosmopolitismo con la aspiración de una ciudadania mundial que realizara plenamente la naturaleza humana (Kant 1992 [1784]: 60-61). Sería así el principio regulador del progreso humano, indicando el horizonte moral hacia donde debe dirigirse la humanidad para cumplir su propio destino como especie (Granja 2003: 220).

La aspiración universalista que anima el cosmopolitismo ante la problemática realidad de la diversidad parece traducirse en un requerimiento de imparcialidad. Así lo habrían entendido los autores que propugnan el procedimentalismo - ya 
sea la Escuela de Frankfurt o Rawls-, como forma de superar los puntos de vista morales sustantivos priorizando las cuestiones de justicia. Sin embargo, estos planteamientos pueden derivar en una consideración abstracta de la humanidad, obviando que las personas se forman como miembros de comunidades concretas. Por ello, el reto del cosmopolitismo consiste precisamente en evitar el desarraigo provocado por la abstracción universalista sin resignarse a la estrechez comunitaria (Muguerza 2004: 20-22). Y, en respuesta a esta disyuntiva, se ha estimulado la reflexión en torno a las posibilidades y limitaciones del concepto de cosmopolitismo, ofreciendo comprensiones renovadas del mismo.

Algunos autores rechazan el predominio de una comprensión política, orientando la mirada hacia las potencialidades que ofrecen los procesos sociales o culturales. Calhoun sostiene que más allá de una equivalencia universal abstracta, el cosmopolitismo se construye a través de las conexiones entre diversos actores en los procesos de interacción específicos que, en forma de relaciones interpersonales o de instituciones sociales, ha ido generando históricamente la humanidad, desarrollando las capacidades para la comprensión mutua. Para superar la inclinación eurocéntrica, Delanty defiende un cosmopolitismo crítico y post-universalista, abierto hermenéuticamente a los distintos modelos de modernidad que representan procesos auto-transformativos que permiten alumbrar un modelo alternativo de sociedad (Delanty 2006, Calhoun 2008).

En ese esfuerzo por engarzar ese horizonte universalista con las realidades políticas y sociales particulares concretas, destaca la idea de elaborar una forma de cosmopolitismo arraigado, aún cuando se exprese en interpretaciones diferentes. Así, puede destacarse la función que realizan los Estados para garantizar el reconocimiento efectivo de los derechos, en su condición de depositarios de la legitimidad. Pero puede enfatizarse también que es mediante la participación en la vida social y política de las comunidades particulares como se desarrollan las virtudes cívicas y se toma conciencia del otro. En ese sentido, la adquisición de la conciencia cosmopolita tendría lugar en las prácticas sociales concretas. Aún así, ciertamente el desafío sigue consistiendo en cómo ampliar los compromisos y fomentar un sentido de ciudadanía global (Kymlicka y Walker 2012). Pues, aun cuando no es posible construir el cosmopolitismo prescindiendo de la pertenencia a las comunidades particulares, es preciso seguir reivindicando aquello que nos hace iguales a los demás (Cortina 2003: 61-70).

El reto del proyecto cosmopolita consiste, así pues, en configurar una noción de ciudadanía que permita integrar equilibradamente la aspiración ética universalista que le otorga sentido y razón de ser — reclamando la dignidad básica de 
todos los seres humanos como fuente fundamental de derechos- con la necesaria inserción en la vida comunitaria - participando de unos determinados valores o patrones sociales - en un contexto de rápido cambio, intercomunicación y mundialización de los problemas, las relaciones y los estilos de vida. En este escenario global en el que pueda perfilarse un horizonte cosmopolita, las ciudades adquieren una importante función en tanto actúan como receptoras materiales de la diversidad y como puente que permite conectar la vida urbana cotidiana con las tendencias y movimientos que actúan a nivel mundial. Desde una perspectiva cosmopolita, se trata de profundizar y actualizar un potencial que las ciudades han ofrecido históricamente, llegar a ser el foro donde se configure la convivencia entre los diferentes.

\section{LA CIUDAD COMO ESCENARIO COSMOPOLITA}

La problemática de una ciudadanía cosmopolita se hace palpable en la compleja convivencia de las ciudades constituidas pluralmente, revelándose aquí no simplemente como una cuestión política, sino primordialmente social y cultural, haciendo referencia a los variados intereses, valores, o estilos de vida que se entrecruzan en el espacio urbano. La ciudad se revela, por ello, como el marco privilegiado donde puede florecer, pese a los desafíos que inevitablemente afronta, el ideal de una sociabilidad cosmopolita ${ }^{7}$. Pues se trata de un escenario en el que la diversidad se manifiesta cotidianamente, planteando demandas dispares y enfrentadas, consitituyéndose así como un foco creativo de actividad y renovación social y política ${ }^{8}$. La confluencia de los movimientos migratorios genera situaciones de interculturalidad, visibilizando modos de vida muy diferentes entre sí (Granja 2003: 222). Puede afirmarse, en ese sentido, que la urbe contemporánea representa un "microcosmos de la globalización" (Mesa 2006: 16). Por ello puede configurarse como un espacio público en el que se exprese la diversidad que la constituye, donde tomar conciencia de la pluralidad de intereses y valores, participando

\footnotetext{
7 Emerge inevitablemente la cuestión de qué tipo de ciudad ofrece las condiciones adecuadas para desarrollar una sociabilidad cosmopolita, entendiendo que factores como el tamaño, la densidad y la heterogeneidad de su población son fundamentales. Aunque habría que atender también a la tradición politica, cultural y religiosa tanto de la propia ciudad como de la región o país en el que se emplaza.

8 Mientras los estados han fomentado históricamente la homogeneización de su población, la expresión de la diversidad étnica y cultural se ha focalizado en los espacios urbanos, conformando las sociedades civiles (Borja y Castells 2000: 35).
} 
conjuntamente en la construcción de una convivencia que apunte hacia un horizonte cosmopolita.

Sennett ofrece una comprensión del cosmopolitismo establecida en relación al despliegue de una sociabilidad y una cultura urbanas. Por ello, se trataría, primariamente, de "la experiencia de la diversidad de la ciudad" (Sennett 2002: 306)". Desde esta perspectiva, el cosmopolita sería el hombre público perfecto, es decir, aquel que sabe moverse en la diversidad, manejándose bien en situaciones que no tienen que ver con aquello que le es familiar (Id. 49). Así, aunque sin renunciar a la senda ilustrada, que se dirigía al horizonte cosmopolita movido por su intrínseco sentido moral, Sennett asimila la influencia de los autores que se habían ocupado de la problemática urbana, como Simmel o los miembros de la Escuela de Chicago, enfatizando las oportunidades que ofrece la interacción urbana para trascender las identidades particulares previamente asimiladas. Significativamente, Wirth percibió que la vida urbana moderna contraría la existencia de identificaciones exclusivas y perdurables, ya que los individuos desempeñan roles segmentados para responder adecuadamente a la variada estimulación que manejan en su discurrir cotidiano por los distintos espacios de una ciudad fragmentada, generándose así unas identificaciones temporales - temporary identification - Si bien el acceso a una experimentación cosmopolita de la diversidad urbana era marcadamente desigual (Id. 298-307).

La caracterización sennetiana del dominio público urbano se adhiere a un modelo performativo, que atiende prioritariamente a los aspectos culturales y comportamentales reconocibles en la interacción cotidiana entre los extraños ${ }^{10}$. Así, se contempla el comportamiento que desarrollan las personas en sociedad por analogía a la representación teatral, tratándose de una forma de auto-dramatización expresiva — self-dramatąing - que actúa como un principio creador de vida pública. A través de la participación interactiva de los diferentes actores se va formando un espacio compartido, definido y estabilizado mediante la creación dinámica de ciertas costumbres y ritos, y el seguimiento de un conjunto de convenciones conforme a las reglas propias de la impersonalidad. Aquí la actuación, entendida como el desempeño de unos roles adecuados, adquiere sentido pleno, posibilitando la comunicación entre los extraños (Sennett 2003: 380-387).

9 Para obtener una visión más completa sobre el pensamiento de Sennett, véase Muñoz Miralles (2014).

10 Este modelo se inscribe en la tradición del teatrum mundi, ejemplificándose en la teoría del role playing de Goffman o en las nociones de teatralidad desarrolladas por Geertz o Sennett (Sennett 2003: 384-386). 
Sennett encuentra en la emergencia de la ciudad moderna en la Europa del XVIII el modelo histórico de formación de un dominio público cosmopolita como forma de encauzar los potenciales conflictos que presenta la diversidad. Estas urbes proporcionaban los lugares — como calles, plazas, cafés, asambleas, mercados - que incitaban a interactuar, donde los individuos podían experimentar cotidianamente la diversidad, llegando a cuestionar la rigidez de las identidades particulares abriéndose a una forma de vida cosmopolita (Halloran: 322-330; Sennett 2002: capítulo 3). Para regular el uso del espacio físico compartido, así como las relaciones entre los diversos grupos, era preciso establecer algún tipo de orden, que fue proporcionado por unos códigos compartidos de índole impersonal que indicaban cómo había que comportarse ante un público formado por extraños. Se trataba de un dominio intrínsecamente problemático, que nunca alcanzaba una constitución definitiva. Pero permitía que la vida en común adoptara una forma de civilidad (Sennett 2002: 19-26; 2008; 2012: 168 ss.). Si bien, se trata de un modelo de interacción social que evidencia sus limitaciones - funcionales, pero sobre todo éticas-, en cuanto se ajusta a un nivel superficial de la misma, expresándose por ejemplo en fórmulas de cortesía, que no requiere explorar una aproximación más profunda al otro. Se trataría, en todo caso, de sortear la conflictividad potencial que inevitablemente acecha en las relaciones cotidianas entre grupos e identidades diferentes, asumiendo el distanciamiento necesario para la conformación y el sostenimiento de un ámbito de actuación impersonal, que no parece dejar margen a la identificación con el extraño (Sennett 2019: 181-186).

Pero la evolución histórica de los espacios públicos urbanos no ha logrado aprovechar las virtualidades que teóricamente ofrece la ciudad para la formación de una sociabilidad cosmopolita, condicionada por las tendencias aislacionistas y defensivas que recurrentemente parecen imponer su dirección en la organización de las comunidades humanas. Sennett considera, desde esta perspectiva, que la parcelación de la ciudad, la homogeneización interna y la carencia de lugares públicos, son factores que desalientan una interacción activa de las diferencias, inhibiendo esa experiencia cosmopolita que se revela básica para la constitución de un dominio público autónomo. Las dificultades relacionadas con la integración y participación se vuelven más acuciantes, de manera que las ciudades amenazan con convertirse en espacios escindidos. Se trata de una problemática que se habría agudizado como resultado de los procesos de globalización y transformación del capitalismo, invitando a repensar la noción de cosmopolitismo.

En las últimas décadas, ciertamente, la urbanización está recibiendo nuevos impulsos procedentes de la globalización y los movimientos migratorios asociados, 
imponiendo nuevos retos para la administración pública así como también para los habitantes urbanos ${ }^{11}$. En las ciudades occidentales conviven hoy en día colectivos muy heterogéneos, tanto por su origen, forma de vida, o situación social ${ }^{12}$. Diversidad que es fuente de riqueza económica y cultural para las sociedades urbanas. Pero que también impone obligaciones más complejas a unas ciudades que disponen de más competencias administrativas (Mesa 2006: 15-17). El riesgo más evidente es que se imponga la tendencia hacia la segregación de la población inmigrante hacia zonas urbanas deprimidas, con menos oportunidades y servicios públicos de menor calidad. La concentración étnica propicia la autoafirmación colectiva frente a los otros grupos, en lugar de favorecer el intercambio y la integración. Como resultado, las distintas minorías tienden a segregarse no sólo de la población dominante, sino también entre sí. En definitiva, las sociedades multiculturales pueden degenerar en sociedades segregadas en las que broten el racismo, fanatismo religioso, y el recurso a chivos expiatorios ${ }^{13}$.

La transformación de la economía global concede a las ciudades un protagonismo renovado, aunque desigual y no carente de contradicciones, actuando en algunos casos como nodos destacados por los que fluyen los flujos financieros y comerciales tanto como los migratorios, dando forma a la nueva economía.

Albert percibió cómo desde los años 80 estaba expandiéndose una actividad económica de alcance global dominada por una lógica financiera de carácter especulativo en detrimento de la industria como eje principal de creación de riqueza, aprovechándose de los procesos de desregulación que permitieron una amplia liberación de capitales, de la innovación tecnológica, o la invención de nuevos productos financieros (Albert 1992: capítulos 7 y 8$)^{14}$. Sennett entiende que se ha propiciado así el acceso de una nueva etapa del desarrollo capitalista, que estaría caracterizada por la globalización económica, el auge de las nuevas tecnologías, el mayor peso adquirido por las finanzas y el comercio, la flexibilización de las

11 La expansión caótica y acelerada de las ciudades emergentes, parrticularmente en Asia, tensiona la capacidad de sus administradores para responder adecuadamente a los retos que se plantean.

12 La gestión urbana se torna aún más compleja debido al incremento de poblaciones flotantes (Borja y Castells 2000: 48-52).

13 Las ciudades europeas podrían seguir la senda de las norteamericanas, donde lejos de consolidarse el modelo de melting pot, se habría intensificado la segregación que produce como efecto una criminalidad crónica (Id. 43-48).

14 La facilidad de mover el capital por el ciberespacio permite obtener rendimientos directos, sin intervención de otros factores de producción (García Roca 1998: 171-173). 
estructuras institucionales y la pérdida de las garantías que ofrecía el estado del bienestar (Sennett 1997: 161). Castells, por su parte, enfatiza el papel central que desempeñan la información y el conocimiento en la configuración de esta nueva economía, generada a partir de las transformaciones organizativas y tecnológicas, tratándose de una forma de economía global que funciona con unos sistemas financieros interconectados y en la que la gestión y la producción se organiza a través de redes (Castells 2006: 27-30) ${ }^{15}$. De esta manera, la actividad productiva de una corporación puede descentralizarse, distribuyéndose en lugares distanciados geográficamente, buscando una reducción de los costes, o externalizar determinadas funciones. Es posible, incluso, para una gran empresa distinguir entre lugar de inversión, lugar de producción, lugar de declaración fiscal y lugar de residencia (Beck 2000: 18). El resultado, en cualquier caso, es una tendencia progresiva hacia la flexibilización de la producción y la fragmentación de las distintas operaciones que realiza la empresa, que contrasta con el funcionamiento unificado que propiciaba el tradicional modelo de estructuración piramidal (Sennett 2006: capítulo 1).

La emergencia de la economía globalizada incita a las grandes empresas a disgregar geográficamente sus distintas operaciones y funciones, localizándose en centros urbanos especializados que conforman una red transnacional, eje de una nueva geografía de la centralidad.

Ese espacio ubicuo estaría así liderado por lo que Sassen denomina ciudades globales, urbes que concentran estratégicamente las operaciones del capital global, desempeñando una función propia coordianadamente con las demás ciudades que integran ese sistema urbano transnacional, para lo que ofrecen servicios especializados o una avanzada infraestructura de telecomunicaciones ${ }^{16}$. Ese nuevo papel implica dejar atrás su función tradicional como centros industriales integradores del territorio circundante, mientras muchas otras ciudades quedarían abocadas a

15 La red consiste en un conjunto de nodos interconectados, sin que haya un centro definido. Cada red se define mediante un programa que asigna los objetivos, establece los criterios de valoración y establece las reglas de funcionamiento. Entre los distintos nodos se establecen canales de comunicación por los que circulan los flujos de información. Los rasgos fundamentales de las redes son: la flexibilidad — la capacidad para auto-reconfigurarse en función de los cambios en el entorno_-, la adaptabilidad — pueden expandirse o reducirse-, y la capacidad de supervivencia - la ausencia de un centro reconocible reduce su vulnerabilidad- (Castells 2006). ${ }_{16} \mathrm{La}$ ciudad global adquiere su sentido propio, pues, como ingrediente principal e impulsor de las redes que constituyen las dinámicas propias de la globalización. Por ello, no se trataría meramente de una megalópolis (Sennett 2019: 133), ni se expresaría adecuadamente a través de otros conceptos, como ciudad-mundo (Sassen 1995: 27). 
ocupar un espacio más marginal (Sassen 1995; 2003: 16). Por ello, se trata de un escenario altamente problemático, en el que la ciudad pasa a desempeñar un papel clave, pero contradictorio.

Así advierte Sennett que la supeditación de la planificación urbana a los intereses del gran capital, ajeno a las necesidades de sus habitantes, redunda en mayor desigualdad y exclusión, renunciando a plasmar una comprensión integral e integradora del espacio urbano, que adquiere así más bien una fisonomía discontinua y fragmentada. Los individuos que no participan del flujo económico principal, se ven empujados a adaptarse explotando los nichos que ofrece una economía informal (Sennett 2019: 131-141). La realización de un proyecto cosmopolita, que promueva unos valores de respeto, integración y solidaridad, así como una cultura urbana abierta al mundo, puede verse claramente amenazada por la preponderancia de los intereses espurios de las corporaciones transnacionales, ahondando, en cambio, en el desarraigo y la desconexión existentes en los espacios urbanos contemporáneos.

No obstante, Castells reclama que, ante el auge de la nueva economía, las ciudades se esfuercen por adoptar un papel protagonista, participando como nodos relevantes de esa red global, ya que aprovechando su capacidad innovadora para atraer personas y capital pueden actuar como generadores de procesos de riqueza. Pero sin olvidar su capacidad social para contrarrestar los efectos desintegradores de una economía que no tiene en cuenta los valores no mercantilizables (Castells 2001: 213-214). Pues inmersas en su dinamismo económico, las ciudades globales pueden fácilmente convertirse es espacios hostiles para quienes los transitan. Aunque también podría encauzarse su vitalidad para propiciar una mayor integración y participación en un proyecto colectivo, revitalizando una cultura urbana nutrida de la pluralidad. En ese sentido, Sassen enfatiza que pese a que las desigualdades que provoca la nueva economía se reflejan en la geografía urbana — contrastando vivamente el estilo de vida de los hombres de negocios internacionales y la precariedad padecida por la mano de obra trasnacional—, ésta sigue ofreciendo, como contrapartida, la posibilidad de generar nuevas nociones de identidad, nuevas formas de pertenencia, y nuevas demandas, invitando a implementar nuevas políticas (Sassen 2003: 15-33). Convendría matizar, no obstante, que el concepto de ciudad global, designando prioritariamente a las urbes que se sitúan en la vanguardia de la globalización financiera y comercial, no alcanza probablemente a reflejar la variedad de situaciones que presentan los diversos núcleos poblacionales a lo ancho del planeta, manteniendo relaciones desiguales con las dinámicas globalizadoras. Aún así, las transformaciones, retos y problemas que conlleva la globalización y 
el modelo imperante de capitalismo afectan notablemente al desarrollo, a la vida social y al gobierno de cualquier sociedad.

Sennett, en relación a ello, aprecia que la incertidumbre, el desarraigo y la estandarización cultural y del entorno que provoca la nueva economía puede atemperarse mediante la reafirmación del lugar a través de la idea de comunidad que impulse una revitalización de la ciudad. Se trata, ciertamente, de un concepto controvertido, particularmente si se reivindica una perspectiva cosmopolita. Pues enfatiza las dimensiones sociales y personales que se asocian al lugar, plasmándose en la pretensión de construir una comunidad mediante la expresión de los valores y creencias compartidos en unas prácticas concretas (Sennet 1997; 2000: 143-145; y 2004: 217).

Pero resaltar las bondades de las relaciones cara a cara desvirtúa un aspecto fundamental de la vida urbana como es la impersonalidad, que requiere el fomento de unas habilidades sociales apropiadas para el trato con los extraños (Sennett 2019: 89 ss.). La idea de comunidad puede incluso adquirir un carácter ficticio, manifestando un sentido hostil, defensivo, frente a la diversidad. El énfasis en aquello que proporciona una identidad distintiva al grupo a lo largo del tiempo requiere un esfuerzo purificador, que recela necesariamente de la mezcolanza y el modo de vida urbano. En ese sentido, añade Sennett que la reivindicación nostálgica de la vida local que propone el nuevo conservadurismo no atiende a la realidad de las grandes urbes configuradas por el capitalismo global, que ya no propician una ligazón geográfica entre familia, trabajo y comunidad (Sennett 2012: 250-252). Así se estaría imponiendo actualmente una percepción negativa de la diversidad, tratándola como fuente de inseguridad amenazante para la cohesión y el orden social, renunciando a aprovechar su potencial para la tolerancia y la creatividad (Raco 2018: 12).

Frente a las versiones armoniosas de la vida común, sustentadas en imágenes de semejanza o en un conjunto de valores y creencias compartidos, Sennett reclama la presencia continua de la conflictividad social como fuente de dinamismo y riqueza, configurando un modelo alternativo de comunidad, entendida como un proceso permanente y abierto ${ }^{17}$. Considera que mediante la implicación activa de los diversos afectados en el tratamiento conjunto de los conflictos inherentes a sociedades complejas — respecto a valores, modos de vida o identidades-, se promueve un esfuerzo recíproco por comunicarse, que va alimentando

\footnotetext{
17 Su defensa de la conflictividad como motor de renovación social se inspira en la sociología de Coser.
} 
un compromiso con lo público que puede sostenerse en el tiempo (Sennett 2000: 150-151). El modelo procesual de comunidad que propone Sennett, forjada sobre sus diferencias internas, se nutre de la comprensión deliberativa de la democracia ${ }^{18}$. Y revela su familiaridad con una comprensión crítica del cosmopolitismo como la que defiende, por ejemplo Delanty, sustentanda en una comprensión procesual de lo social, entendiendo que la apertura al mundo señala la capacidad autorreflexiva y crítica de las sociedades como fuente de transformación (Delanty 2006: 34-43). El modelo social que propone Sennett sería plural y abierto a influencias diversas, obteniendo su dinamismo de la conflictividad que lo constituye. En la medida en que la existencia de la pluralidad sea asimilada constructivamente, propiciando la renovación de las identidades y los modos de relación, puede ir conformándose una sociedad abierta, cosmopolita y democrática.

La teoría deliberativa se distingue por situar en primer plano los procesos mediante los que se forma la voluntad, por los que se llegan a acuerdos o se mantienen los desacuerdos, pudiéndose producir una transformación de las preferencias. Se trata de que las diferentes posturas o ideas puedan ser justificadas argumentativamente, lo que conlleva un compromiso con la racionalidad y la imparcialidad en la discusión (Elster 2001: 21-23). Desde esta perspectiva, se entiende que la clave de un proceso democrático no radica tanto en el momento de la decisión - que suele obedecer a la regla de la mayoría-, sino en la posibilidad de examinar conjuntamente las razones que aportan los distintos afectados, lo que requiere de un esfuerzo de reflexión, apertura y consideración ante las razones de los demás, incluyendo la revisión de los propios planteamientos. Para Gutmann y Thompson el propósito del debate no es alcanzar puntos de encuentro definitivos, sino establecer un suelo común en el que puedan convivir respetuosamente las diferencias. El objetivo no sería llegar al consenso, sino más bien lograr una reducción razonable de las discrepancias a partir del intercambio público de razones. Se revelaría así el carácter procesual y abierto de la deliberación, que lleva a la considerar sus resultados como provisionales (Gutman y Thompson 2004: 6). Se trataría de una propuesta que promueve la incorporación activa de las minorías al debate público, entendiendo que la convivencia democrática en una sociedad plural no puede establecerse sobre

\footnotetext{
18 Sennett considera que en su origen la democracia enraíza en los espacios cívicos que ofrece la ciudad, favoreciendo la toma de conciencia de existencia de las diferencias, impulsando la consideración de las diversas perspectivas, y creando un ambiente propicio para la discusión pacífica sobre los intereses enfrentados. Es imprescindible, por ello, que proporcione espacios donde las diferencias pueden interactuar, evitando la disgregación. (Sennett et al. 2016: 6-9).
} 
el mero predominio de la voluntad mayoritaria. Por ello, cabe colegir que es una comprensión de la democracia proclive a la realización del ideal cosmopolita.

Sennett enfatiza, en ese sentido, que a través de la deliberación pública los ciudadanos pueden tomar conciencia de puntos de vista ajenos, explorar formas alternativas de actuar, pensar y vivir que no ofrecen un fácil encaje, e ir estableciendo unos equilibrios parciales y revisables que permitan sostener la convivencia en el tiempo (Sennett 1999) ${ }^{19}$. La deliberación sería, así pues, el camino que permite explorar cooperativamente la posibilidad de desarrollar proyectos comunes a partir de las divergencias que conforman una sociedad compleja, de manera que las discrepancias se puedan tratar mediante un intercambio constructivo de razones.

El dominio público cosmopolita, desde esta perspectiva, sería aquel que puede evolucionar en el tiempo como un espacio abierto y democrático, mediante procesos deliberativos, ya que la expresión e interacción de las distintas voces e intereses genera su propia dinámica de cambio y evolución de la vida pública. Se trata, así pues, de explorar cooperativamente la elaboración de proyectos comunes a partir de las divergencias que conforman una sociedad compleja, afrontándolas mediante un intercambio constructivo de razones. En ese sentido, Sennett propone entender el espacio público urbano a la manera de una linde, una zona de transición entre diferentes territorios que, a diferencia de las fronteras — que aíslan a los diferentes grupos entre sí-, propiciaría el encuentro e interacción expresiva entre las diferencias (Sennett 2006b; 2008; y 2012: 88-89).

Frente a los anhelos comunitaristas de armonía e integración en torno a unos valores compartidos, Sennett insiste en en reivindicar las virtudes de la sociabilidad urbana para constituir una vida común civilizada entre los extraños. Tal sería, precisamente, el sentido del cosmopolitismo que propone el sociólogo estadounidense. Es decir, consistiría en la forma de vida que es posible establecer en un espacio ocupado por actores diversos cuando se esfuerzan por trascender sus perspectivas ideológicas o vitales para tomar en consideración los puntos de vista, intereses o necesidades ajenos, con vistas a hacer posible una convivencia que

${ }^{19}$ La conexión con el otro, según Sennett, se impulsa mediante dos mecanismos, la simpatía y la empatía. La primera se basa en una identificación emocional con el otro, lograda por la imaginación. La empatía, por contra, sería una forma de adquirir conciencia del otro sirviéndose de la curiosidad, que anima a salir de uno mismo. De esta manera, es posible reconocer al otro en sus propios términos, despertando el interés por las personas tal y como y son, sin pretender alcanzar una identificación plena. Se trata de una habilidad susceptible de interiorizarse y plasmarse en forma de hábito, a través de un proceso en el que el propio yo es transformado. Véase Muñoz Miralles (2014). 
se renueva permanentemente asumiendo la problematicidad inherente. De esta forma, en el espacio urbano se va elaborando una forma distintiva de sociedad al tiempo que ofrece un proyecto de desarrollo personal.

Por un lado, así pues, el cosmopolitismo sennetiano indicaría una forma de sociabilidad, que es elaborada performativamente por los extraños como respuesta primordial a los requerimientos cotidianos de comunicación, intercambio o resolución de problemas convivenciales. Por otro, permite perfilar un ideal humano que se expresa en la figura del urbanita implicado en el trato con las diferencias, participando activamente de los retos que plantea, mientras aprende a moverse en ese territorio heterogéneo del que puede también obtener experiencias variadas que le estimulan a ir madurando como persona. La cuestión que surge es si esta propuesta constituye una base suficiente para elaborar un concepto consistente de ciudadanía cosmopolita.

Se echa en falta, a mi juicio, la perspectiva de la justicia para conceder legitimidad a los acuerdos o principios que establecen la vida en sociedad, así como para valorar las conductas de los actores. Pues "la socialidad es la capacidad de convivencia, pero también de participar en una sociedad justa, en la que los ciudadanos puedan desarrollar sus cualidades y adquirir virtudes" (Cortina, 2005: 46). Y, en ese sentido, cabe reconocer la civilidad no meramente como una forma de sociabilidad que permite pacificar la interacción entre extraños. Pues se debería entender primordialmente como una virtud moral, cuyo ejercicio fomenta la adhesión de los ciudadanos a un proyecto compartido (Id.24-26). Es decir, no es suficiente con plantear las bondades de una actitud abierta o empática ante las diferencias, sino que es preciso fundamentar unos principios de justicia sobre los que establecer la convivencia y orientar las conductas públicas deseables. Se trata de retornar al fundamento moral del cosmopolitismo. Si bien, ciertamente, el recurso del planteamiento senenttiano a la teoría deliberativa permite ahondar en una concepción inclusiva de la democracia, apostando por un enfoque constructivo sobre la presencia de las diferencias en un espacio compartido. Pero, en definitiva, se vuelve ineludible la necesidad de educar a los ciudadanos en el cosmopolitismo, incorporando un sólido sentido de justicia y de solidaridad (Cortina 2004).

Por otro lado, hay que insistir en que más allá de la participación en los espacios impersonales y diversos que ofrecen las ciudades modernas, la idea cosmopolita se refiere a una dimensión fundamental de la persona, de índole intrínsecamente moral, y que se distingue por apuntar a la universalidad, enfatizando consecuentemente la identidad básica de todos los seres humanos. Por tanto, no puede reducirse a la mera conformación de una forma de sociabilidad apropiada para la interacción 
entre grupos diferentes que se ven forzados a compartir un territorio definido. Más aún en un mundo en el que las posibilidades de comunicación e intercambio de información se han multiplicado, desbordando cualquier planteamiento que revele una consideración localista de las relaciones entre los diversos actores y grupos sociales. La defensa de una ciudadanía cosmopolita implica, según se ha visto, la necesidad de establecer instituciones y espacios de debate de índole transnacional.

\section{Conclusiones}

Según ha tratado de mostrarse, las complejidades del mundo actual reclaman una actualidad renovada de la idea cosmopolita, requiriendo un esfuerzo por repensar su contenido, función, limitaciones y posibilidades para adecuarlo a las exigencias del presente. La expansión de los procesos globalizadores está suponiendo en muchos momentos una fuente de desequilibrios económicos y sociales, más allá de las oportunidades que ofrece para la interconexión y comunicación planetaria, que propiciarían en principio la consolidación de una comprensión cosmopolita de las relaciones humanas. Sin embargo, en los últimos años parecen multiplicarse las reacciones defensivas, el retorno a unas concepciones tribales y particularistas que desafían la aspiración universalista y abierta al encuentro con las diferencias que anima el cosmopolitismo. Por ello, es ineludible incidir en la necesidad de fomentar un proyecto que sitúa en su núcleo al ser humano como tal, más allá de las contingencias propias de las adscripciones identitarias particulares, y que por ello, revela su fundamento inequívocamente moral.

Aun cuando pueda ponerse el acento en las cuestiones de índole política o jurídica, o se plantee como un tema cultural, representando una actitud o un estilo de vida, conviene enfatizar que el valor del cosmopolitismo radica precisamente en subrayar la identidad básica de todos los seres humanos, relativizando el peso de lo particular como fuente de diferenciación. Si bien reconociendo la aportación de las diferentes culturas o modos de vida para el acervo común de la humanidad, es decir, se trata de fomentar un compromiso moral con el otro, considerando su diferencia desde el reconocimiento de nuestra identidad humana fundamental.

En ese sentido, la ciudad se revela como el espacio físico en que de manera palpable se encuentran las diferencias, surgiendo una amalgama de problemas y oportunidades para la convivencia, convirtiéndose por ello en una especie de escuela o taller para el cosmopolitismo. La evolución de los nuevos contextos urbanos, móviles, variables, fragmentados y aparentemente desorganizados, plantea ciertamente un reto mayor para la realización de este ideal, así como para la 
inserción en un proyecto común de los diferentes individuos y grupos que pueblan la geografía urbana contemporánea. Las ciudades adquieren un papel crucial en el escenario de la globalización, aunque fuertemente condicionado por los intereses de un capital ubicuo y ajeno a las necesidades ciudadanas. Por ello, su gestión debería comprometerse con un modelo nítidamente democrático, abriéndose a la participación de los afectados por las decisiones, apostando por la implantación de políticas que afronten adecuadamente los retos del mundo globalizado, tendentes a la reducción de las desigualdades, la inclusión social y la sostenibilidad. En este marco, emerge a mi juicio la necesidad de una forma de ciudadanía que responda creativamente a la complejidad del mundo actual, agudizada por una difuminación de las instituciones que tiende a abandonar a los individuos a su suerte.

Ciertamente, permanecen abiertas muchas de las cuestiones vinculadas a la posibilidad de una ciudadanía cosmopolita en un mundo globalizado y crecientemente complejo, especialmente los problemas de legitimidad y participación democrática, de pertenencia e identidad, de desigualdad y desequilibrios globales, o de uniformización de los entornos y los estilos de vida.

Las propuestas de Sennett, aun cuando se antojan insuficientes como respuesta a los problemas planteados, sí que ofrecen un notable interés a la hora de ir definiendo ese proyecto cosmopolita inserto en las realidades cotidianas en las que tiene lugar en el encuentro o el choque de las diferencias, pero en las que puede brotar la conciencia de la diferencia y la unidad. Es por ello que incide en la vinculación íntima entre democracia y cosmopolitismo, dando lugar a una forma de vida que fomenta la participación y la convivencia activa de la diversidad. En el esfuerzo por comprender y reconocer al otro, se revela la orientación moral fundamental que debe nutrir todo proyecto cosmopolita.

Pero el ideal cosmopolita requiere ir más allá del marco que ofrece la sociabilidad urbana - más aún atendiendo a las limitaciones atribuidas al modelo de civilidad así como a la influencia creciente de unas dinámicas sociales y comunicativas que desbordan el ámbito de la proximidad — aspirando a alcanzar un horizonte de universalidad. Es decir, es preciso incidir en el núcleo moral del cosmopolitismo, reforzando la idea de una ciudadanía que, sin renunciar a la pertenencia comunitaria, se nutra de valores humanos universales — ahondando en la idea de un cosmopolitismo arraigado - , siendo participe de la institucionalización de procesos de decisión colectiva de dimensión global.

\author{
Albert Muñoz Miralles \\ Universitat Jaume I \\ albertmumi@yahoo.es
}




\section{BibliografíA}

Albert, M. (1992): Capitalismo contra capitalismo, Buenos Aires: Paidós.

BECK, U. (2000): ¿Qué es la globalización? Falacias del globalismo, respuestas a la globalización, Barcelona: Paidós.

Borja, J. y Castells, M. (2000): “La ciudad multicultural”, en D. Jiménez (comp.), Laberintos urbanos en América Latina, Quito: ABYA-YALA, pp. 35-56.

Calhoun, C. (2008): "Cosmopolitanism in the modern social imaginary", Dedalus, vol. 137(3), pp. 105-114.

Castells, M. (2001): "La ciudad de la nueva economía", Papeles de población, no 27, pp. 207-221.

CAstells, M. (2006): La sociedad red. Una visión global, Madrid: Alianza.

CortinA, A. (2000): "Ética y política:Moral cívica para una ciudadanía cosmopolita", Endoxa, no 12 , pp. 773-789.

CortinA, A. (2003): "Educar en un cosmopolitismo arraigado", Paidea, no 30, pp. 61-70.

CortinA, A. (2004): "Educar para una ciudadnía cosmopolita”, El País, 11-02-2204.

Cortina, A. (2005): Ciudadanos del mundo. Hacia una teoría de la ciudadanía, Madrid: Alianza.

Delanty, G. (2006): "The cosmopolitan imagination: critical cosmopolitanism and social theory", The British Journal of Sociology, vol. 57 (1), pp. 25-47.

Elster, J. (comp.) (2001): La democracia deliberativa, Barcelona: Gedisa.

García MArzÁ, D. (2013): “La dimensión ética del diseño institucional”, en E. González Esteban (ed.), Ética y gobernanza: un cosmopolitismo para el siglo XXI, Granada: Comares, pp. 31-58.

García Pascual, C. (2003): “Ciudadanía cosmopolita”, Cuadernos electrónicos de Filosofía del Derecho, no 8 , pp. 4-23.

García RocA, J. (1998): “Globalización: Un mundo único desigual y antagónico”, en A. Cortina (dir.), 10 Palabras Clave en Filosofía política, Estella: Verbo divino.

GONZÁLEZ EsTEBAN, E. (2013): "De la gobernanza política a la gobernanza cosmopolita", en E. González Esteban (ed.), Ética y gobernanza: un cosmopolitismo para el siglo XXI, Granada: Comares, pp. 3-30.

Granja, D. M. (2010): Lecciones de Kant para hoy, Barcelona: Anthropos.

Gutman, A. y Thompson, D. (2004): Why deliberative democracy?, N. Jersey: Princeton U.P.

Halloran, M.S. (1981): "Public and Private: Richard Sennett on Public Life ans Authority", Quarterly Journal of Speech, vol. 3, pp. 322-330.

IgArashi, H. y SAITO, H. (2014): "Cosmopolitanism as cultural capital: Exploring the intersection of globalization, education and stratification", Current Sociology, vol. 8(3), pp. 222-239.

KANT, I. (1992): "Idea de la historia universal en un sentido cosmopolita", en Filosofía de la historia, Madrid: FCE [Edic. Orig. 1784].

KymlickA, W. y Walker, H. (2012): Rooted cosmopolitanism: Canada and the world, Vancouver: UBC Press. 
LipoveTSKY, G. (2011): "El reino de la hipercultura: cosmopolitismo y civilización occidental”, en G. Lipovetsky y H. Juvin, El occidente globalizado, Barcelona: Anagrama, pp. 11-102.

Mesa, M. (2006): "Globalización, ciudadanía y derechos: la ciudad multicultural", Papeles de cuestiones internacionales, $\mathrm{n}^{\circ}$ 95, pp. 11-21.

Muguerza, J. (2004): "Cosmopolitismo y derechos humanos", en V. Serrano Marín (coord.), Ética y globalización. Cosmopolitismo, responsabilidad y diferencia en un mundo global, Madrid: Biblioteca Nueva, pp. 83-110.

MuÑoz Miralles, A. (2014): La construcción del carácter frente a las contradicciones del nuevo capitalismo en Richard Sennett [Tesis doctoral], Castellón de la Plana: Universitat Jaume I.

NAvA, M. (2006): "Domestic Cosmopolitanism and Structures of Feeling: the Specifity of London", en N. Yuval-Davis, K. Kannabiran y U. Vieten (eds.), The Situated Politics of Belonging, Londres: Sage, pp. 42-53.

RACO, M. (2018): "Critical Urban cosmopolitanism and the governance of urban diversity in European cities", European Urban and Regional Studies, vol. 25 (1), pp. 8-23.

SÁDABA, J. (2003): "Educación y cosmopolitismo", Daimon, no 30, pp. 95-104.

SASSEN, S. (1995): "The Global City: Introducing a Concept", The Brown Journal of World Affairs, vol. 11 (2), pp. 27-43.

SASSEN, S. (2003): Los espectros de la globalización, Buenos Aires: FCE.

SennetT, R. (1997), “The New Capitalism”, Social Research, vol. 64 (2), pp. 161-180.

SENNETt, R. (1999): "The spaces of democracy", Harvard Design Magazine, vol 8, pp. 68-72.

SENNETT, R. (2000): La corrosión del carácter. Las consecuencias personales del trabajo en el nuevo capitalismo, Barcelona: Anagrama.

Sennett, R. (2002): El declive del hombre público, Barcelona: Península [Edic. Orig. 1974]

SennetT, R. (2003): "Reflections on the Public Realm", en G. Bridge y S. Watson (eds.), A companion to the City, Oxford: Blackwell, pp. 380-387.

SennetT, R. (2004):"El capitalismo y la ciudad", en A. Martín Ramos y F.Chocey (eds.), Lo urnbano en 20 autores contemporáneos, Barcelona: Univesitat Politècnica de Catalunya, pp. 213-220.

SENNETT, R. (2006a): La cultura del nuevo capitalismo, Barcelona: Anagrama.

SENnETT, R. (2006b): "The open city" (conferencia), Berlin: Urban age.

SENNETT, R. (2008): “Quant. The Public Realm”, URL=http://www.richardsennett.com/ site/SENN/Templates/General2.aspx?pageid=38. Consultado el:

SENNETT, R. (2012): Juntos. Rituales, placeres y politica de la cooperación, Barcelona: Anagrama.

SENnETT, R. et al. (2016): Designing Politics: the limits of design. Londres: LSE

SENNETT, R. (2019): Construiry habitar. Ética para la ciudad, Barcelona: Anagrama.

SkovgaARD-Smith, I. y Poulfelt, F. (2018): "Imaging 'non-nationality`: Cosmopolitanism as a source of identity and belonging", Human Relations, vol. 71 (2), pp. 129-154.

Vertovec, S. y Cohen, R. (2002): "Introduction: Conceiving Cosmopolitanism”, en S. Vertovec y R. Cohen, Conceiving Cosmopolitanism: Theory, Context, and Practice, Oxford U. P., pp. 1-22. 